\title{
Comprehensive Study of Radio over Fiber with different Modulation Techniques - A Review
}

\author{
Abhishek Sharma \\ Assistant Professor, \\ Department of ECE, \\ Sri Sai University, Palampur, India
}

\author{
Savita Rana \\ M.Tech Scholar, \\ Department of ECE, \\ Sri Sai University, Palampur , India
}

\begin{abstract}
With the increase in the technology of networks and the internet, the need of the users also increases. The requirement of high bandwidth, high data transmission rate etc increases. To fulfill this need the concept of fiber optic was developed. Fiber optic communication is optical communication which is the combination of two communication methodologies and can be used for both wired and wireless communication systems. This form of communication is used by the users from many years but still it requires some advancements and developments to make it more refine. The conventional systems designed for RoF technology comprises of various drawbacks such as limited number of users, unwanted frequencies in the signals and quality of the system. This paper provides a brief to the concept of fiber communication and various modulation schemes along with this the developments that had been done in this work are also define in related work section.
\end{abstract}

\section{Keywords}

Radio Over Fiber, Optical Communication, Modulation, Bandwidth

\section{INTRODUCTION}

Fiber Optical communication uses the fiber optical cables as the medium of transmission and transfers the data in the form of light. It is widely used to facilitate the users to access the $3 \mathrm{G}$ and Wi-Fi networks simultaneously from the equal antennas [1]. The figure1 (below) depicts the process of optical communication system.

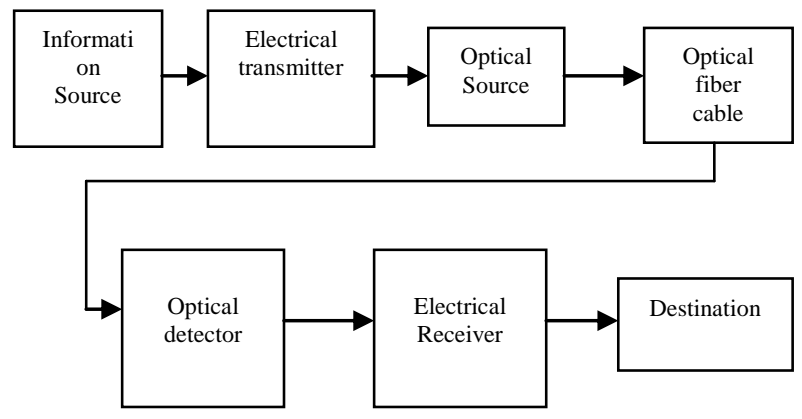

Fig 1 Optical Communication System [1]

In other form radio alerts are extracted over fiber optic cable. Hence this results to increase the capability of the single antenna to hold the any or all the radio alerts whether it comes from 3G, Wi-Fi, mobile networks etc [3][4], carried over the single fiber optical transmission cable. Whereas traditionally this was done by applying the concept of protocols in which the antennas was replaced by separate devices. Radio over fiber transmission is used for various modules such as cable Television networks, satellite base stations etc [6].
In RoF structures, Wi-Fi alerts are transmitted in optical shape among vital nodes and a hard and fast of (BS) base stations earlier than being emitted through air [7]. Every base station is modified to communicate to the mobile user's station which is located inside the different base stations [8]. The benefit is that the devices used for $\mathrm{Wi}-\mathrm{Fi}, 3 \mathrm{G}$ and other protocols can be centralized devices which are fixed to a single centralized location with far off antennas which are connected by fiber optic cables [9]. Significantly, it lessens the devices and maintenance value of the communication system [10]. The figure 2 depicts the concept of radio over fiber communication system.

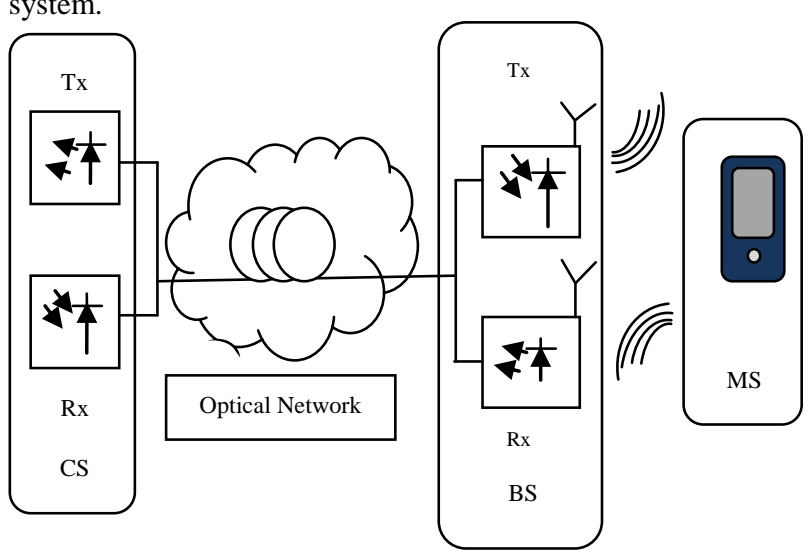

Fig 2 concept of radio over fiber system [10]

The classification of the radio over fiber communication system is done in two sub parts on the basis of frequency limit of the carrier signals which is transmitted over the channel. This categorization is named as follows [11]:

1. RF-over-Fiber

2. IF-Over-Fiber

a) In RF-over-fiber structure, a carrier signal which imposes the high frequency value is loaded over the light wave signal. On the base station the carrier signals are received at excessive frequency and then the converted to the electric format from optical format and then the signals are emitted by using the antennas [12-17]. This leads to the elimination to the requirement of the frequency updown conversion at different base stations. Therefore ensuing in easy and substitutable implementation is activated at the bottom stations.

b) In IF-over-fiber structure, an IF (intermediate frequency) radio signal with a lower frequency is used for modulating earlier than being transported over the optical link. Consequently [18], before radiation through the air, the signal should be up-converted to RF at the base station. 
Numbers of simulation equipment can be used to layout RoF structures. Popular commercial equipment were advanced with the aid of Opti wave systems Inc. and VPI photonics [19].

\section{ARCHITECTURE OF ROF}

In mobile and $4 \mathrm{G}$ networks, the concept of micro and pico cells is the pioneering approach [20]. The idea behind opting this concept by the $4 \mathrm{G}$ network is to enhance the capacity of the system along with the better hotspot. Let us consider a RoF system with average range cell exposure at millimeter band. Because of high valued frequency and vital surrounded absorption, one can shift to pico and micro cells enclosed or all fresco situation respectively [21].

The Radio over Fiber is a system which consists of various modules such as central office i.e. CO, a PON network, a mobile transceiver and a base station as shown in figure 3 below [22]:

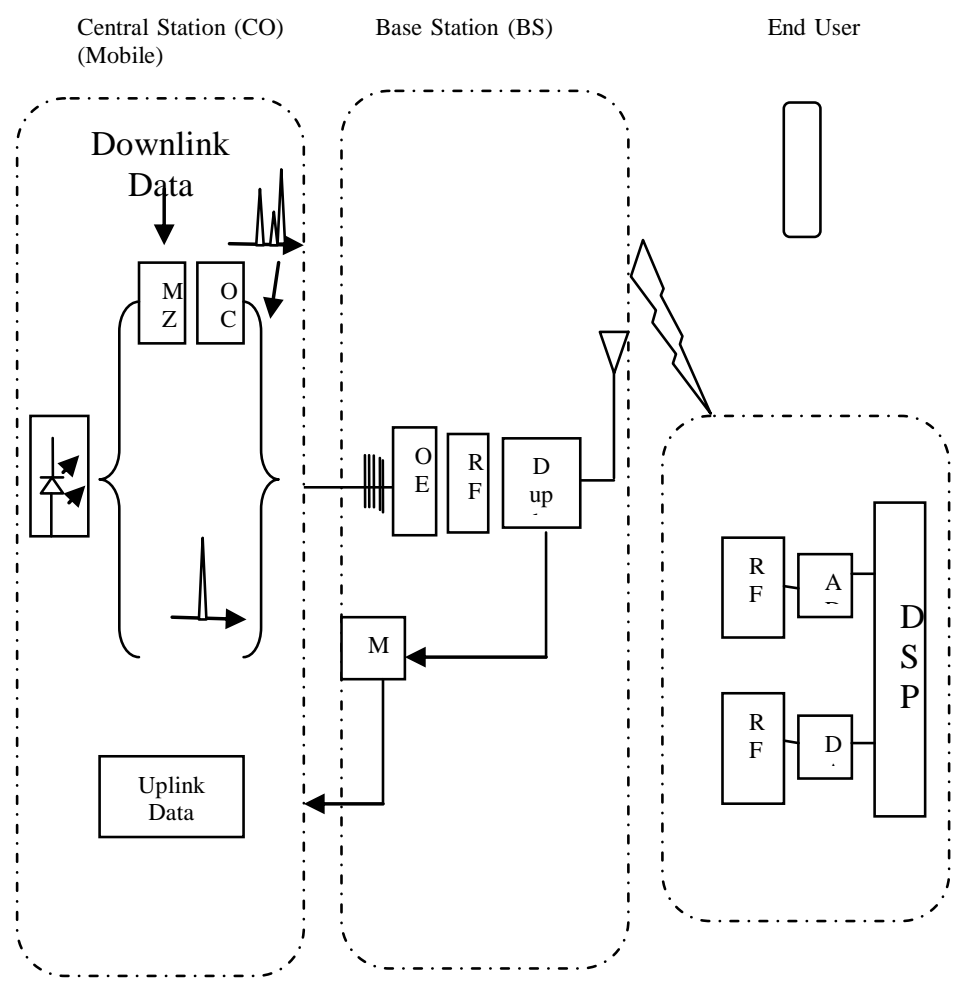

Fig 3 Architecture of RoF

At first the central office generates a $1550 \mathrm{~nm}$ optical carrier and then it is sub divided into pair by using splitters. The first sub part of the pair is modulated $5.28 \mathrm{Gbps}$ by using 16 QAM signals. Then the optically modulated carrier or signal is transferred to the Mach-Zehnder modulator by using the OCS i.e. Optical Carrier Suppression so that the wave of $60 \mathrm{GHz}$ can be generated. The second part of the pair is concatenated with signal that is modulated and then it leads to the resulting signals which are transferred over $20 \mathrm{~km}$ fiber optical link [23].

\section{MODULATION}

Modulation is process in which causes the fluctuation in the carrier signals with a modulated signal which comprises of information which is going to be transmitted. Modulation can be applied by using the modulator and the it is classified in the following forms [24].
- $\quad$ Amplitude Shift Keying i.e. ASK

- $\quad$ Frequency Shift Keying i.e. FSK

- $\quad$ Phase Shift Keying i.e. PSK

- $\quad$ Binary PSK i.e. BPSK

- $\quad$ QPSK (Quadrature Phase Shift Keying)

- $\quad$ DPSK (Differential PSK)

- $\quad$ QAM (Quadrature amplitude modulation)

3.1 ASK: Amplitude Shift Key is the modulation in which the amplitude of the carrier signals varies but the frequency and the phase remains constant. The strength or amplitude lies between 0 and 1 [25]. But the value of the amplitude did not vary constantly.

3.2 FSK: Frequency Shift Key is a modulation which causes the variation in the frequency of the signals. The value ranges between binary 0 and 1 . In this the value of the amplitude and phase remains constant or unchanged during the bit interval[26].

3.3 PSK: In Phase Shift Key modulation the frequency and the amplitude of the carrier signals remain unchangeable. The phase of the signals keeps varying over the bit stream[27-28].

3.4 DPSK: Differential Phase Shift Key which expresses the data by altering the phase of carrier signals.

3.5 BPSK: Binary PSK is another form of PSK in which there are two phases corresponding to a [29] carrier signals and these phases are located at the distance of $180^{\circ}$. It is also referred as 2-PSK. The equation used for this is as follows:

$$
S_{n}(t)=\sqrt{\frac{2 E_{b}}{T_{b}} \cos \left(2 \pi f_{c} t+\pi(1-n)\right), n=0,1}
$$

3.6 QPSK: The full form of the QPSK is Quadrature PSK. According to the constellation diagram it has 4 points. Its capability is measured to encode the two bits per symbol [30]. The equation used for QPSK modulation is:

$$
\begin{gathered}
\delta_{n}(t)= \\
\sqrt{\left.\frac{2 E_{s}}{T_{s}} \cos \left(2 \pi f_{c} t+(2 \pi-1) \frac{\pi}{4}\right), n=1,2,3,4\right)}
\end{gathered}
$$

3.7 QAM: Quadrature Amplitude modulations there are two carrier signals which shares same frequency but with dissimilar value of the phase by $90^{\circ}$. The first carrier signal is knows as I signal and the second is referred as Q signal[3137]. These signals are represented by sine and cosine waves.

\section{RELATED WORK}

Vishal Upadhyaya, (2014) [1], After seeing such a drastic increase in the users of optical fiber communication this work presents a Radio over Fiber communication technique and the analysis was performs over various quality factors that can effect it. The comparison was performed on the basis of various modulation techniques such as QPSK, PAM, PSK, DPSK etc.

A.M. Zin, (2010) [2], mobile and wireless networks are in trend now days. The requirement of wireless network is increased in order to overcome the various points such as to reduce the cell size so that large number of users can accommodated to it, to implement the microwave/millimeter waves so that the congestion in lower frequency bands can be removed. In order to create a reliable and efficient network the consisted bases station should be cost effective. 
Cost effective base stations that incurred less cost to buy and install them developed to achieve success in the market. So the optical fiber is used for removing theses discrepancies because it has various properties such as it facilitates the users with wider bandwidth, high rate of data transmission, loss less medium of data transmission, Optical fiber communication medium has various features such as very high bandwidth, light weight, higher flexibility and cheaper to buy makes it more suitable for RoF. This lightens the various milestones in this technology.

Jincy john, (2012) [6], Fiber Optical communication has various plus points such as it supports data transmission in optic waves along with wider bandwidth. The WiFi with fiber optic cable provide real time multimedia facility to the users. The proposed work is simulated using Optisystem 10 and RF wireless systems pooled with optical fiber link model. The results of proposed work are shown in the form of parameters such as BER and Q-factor. The simulation is performed in MATLAB.

Pooja (2015) [11], Author described that the RoF is technology which is incorporation of wireless and fiber optic networks. It is the most prominent technology preferably employed to access the broadband. In this paper the focus was to describe the advantages and disadvantages. The different mechanisms that are used to transmit the radio carrier signals by using fiber were also highlighted in this study.

Naresh Kumar (2012) [12], as given in this paper the radio over fiber can be defined as technology which can be used to monitor the traffic over the wireless communication system. It is a collection of two technologies i.e. fiber optics and wireless networking. Since it comprises of fiber optic technology, it transfers the data in the form of light. This study enlightens the techniques, applications, benefits and disadvantages of the radio over fiber communication system.

Table1 Literature Table

\begin{tabular}{|c|c|l|l|}
\hline $\begin{array}{c}\text { S. } \\
\text { No. }\end{array}$ & Author's Names & \multicolumn{1}{|c|}{ Topics } & \multicolumn{1}{c|}{ Objectives } \\
\hline 1. & $\begin{array}{c}\text { Vishal } \\
\text { Upadhyaya, } \\
(2014)[1],\end{array}$ & $\begin{array}{l}\text { Comparative Analysis of Different } \\
\text { Modulation Techniques using ROF } \\
\text { in Optical Communication System }\end{array}$ & $\begin{array}{l}\text { To analyze the performance of the fiber optic communication } \\
\text { system by using QPSK, PAM, DPSSk, PSK modulation schemes. }\end{array}$ \\
\hline 2. & $\begin{array}{c}\text { A.M. Zin, (2010) } \\
{[2],}\end{array}$ & $\begin{array}{l}\text { An overview of radio-over-fiber } \\
\text { Networks Technology }\end{array}$ & $\begin{array}{l}\text { The aim behind conducting this study was to analyze various } \\
\text { milestones in the field of fiber optic communication. }\end{array}$ \\
\hline 3. & $\begin{array}{c}\text { Jincy john, (2012) } \\
{[6],}\end{array}$ & $\begin{array}{l}\text { Design and simulation of a radio } \\
\text { over fiber system and its } \\
\text { performance analysis }\end{array}$ & $\begin{array}{l}\text { To develop an integrated communication system by combining RF } \\
\text { wireless and optical fiber by using optisystem10 platform. }\end{array}$ \\
\hline 4. & $\begin{array}{c}\text { Pooja (2015) } \\
{[11],}\end{array}$ & $\begin{array}{l}\text { Advantages and Limitation of } \\
\text { Radio over Fiber System }\end{array}$ & $\begin{array}{l}\text { This was a review study that represents various advantages and } \\
\text { disadvantages of radio over fiber communication system. }\end{array}$ \\
\hline 5. & $\begin{array}{c}\text { Naresh Kumar } \\
\text { (2012) [12] }\end{array}$ & $\begin{array}{l}\text { A Review Paper On Radio Over } \\
\text { Fiber Technology }\end{array}$ & $\begin{array}{l}\text { This study was a overview to the applications, drawbacks, benefits } \\
\text { and techniques that are used in radio over fiber communication. }\end{array}$ \\
\hline
\end{tabular}

The table above gives an overview to the related work that had been conducted in this field in order to perform various analytical studies.

\section{CONCLUSION}

With growing ages, the means of communication are also enhanced. Initially the communication was performed by using wired communication media but it was not possible to do communication over a large distance. Therefore the concept to wireless communication comes to existence and from wireless communication the technology gives birth to the optical communication which uses fiber optic mediums for communication. The increasing trend of optical communication leads to the various flaws in it.

This study comprises of introduction to the RoF communication system. The various modulation techniques such as QAM, DPSK, PSK are also described in this. The milestones in this field are also After studying the related work of this field it is concluded that there is need to do more work on the various quality factors like increase in bandwidth, to enhance the number of users that can participate in the communication simultaneously. Hence further enhancements can be done in order to remove these flaws form the communication system by using trendy mechanisms.

\section{REFERENCES}

[1] Vishal Upadhyaya et al, (2014), “Comparative Analysis of Different Modulation Techniques using ROF in Optical Communication System”, IJCET, Vol 4, Issue 3

[2] A.M. Zin,"An overview of radio-over-fiber Networks Technology”, IEEE, Pp 1-3, 2010,

[3] Vagheshe Antony, (2015), "Performance Improvement and Cost Reduction Techniques For Radio Over Fiber Communications", IEEE, Pp 1-45

[4] Ting Su,(2015) "Bidirectional multiband radio over fiber system based on polarization multiplexing and wavelength reuse", IEEE vol 23(8), Pp 1-5

[5] Sara Rebhi,(2014), "Perform evaluation of radio over fiber System at $60 \mathrm{HGz}$ for outdoor and indoor environment", IEEE, Pp 1-4

[6] Jincy john, (2012) "Design and simulation of a radio over fiber system and its performance analysis", IEEE, Pp 636-640,

[7] Fabrice Mfuamba, (2016) "Adaptive performance improvement of fiber Bragg grating in radio over fiber", Scientific research, vol 4, Pp 1-6

[8] Lin cheng, (2015) "Coordinated Multipoint Transmissions in Millimeter-Wave Radio-over-Fiber Systems", IEEE, Pp 1-8 
[9] Anthony Ng'oma, (2013) "Radio-over-Fiber Technologies for Multi-Gb/s Wireless Applications", IEEE, Pp 1-3

[10] Junwen zhang (2016), "Full-Duplex Quasi-Gapless Carrier-Aggregation using FBMC in Centralized Radioover-Fiber Heterogeneous Networks”, IEEE, Pp 1-7

[11] Pooja, (2015), “Advantages and Limitation of Radio over Fiber System “,ijcsmc, Vol. 4, Issue. 5, pg.506 - 511

[12] Naresh Kumar, (2012), “ A Review Paper On Radio Over Fibre Technology”, ijaer, Vol.7 No.11

[13] Sharma, Vishal, and Sushank Kumar. "Empirical evaluation of wired-and wireless-hybrid OFDM-OSSBRoF transmission system." Optik-International Journal for Light and Electron Optics 124.20 (2013): 4529-4532.

[14] Sharma, Vishal, and Sushank Kumar. "Hybrid OFDMOSSB-RoF transmission system incorporating fiber Bragg grating." Optik-International Journal for Light and Electron Optics 124.20 (2013): 4670-4672.

[15] Amphawan, Angela, and Sushank Chaudhary. "Freespace optical mode division multiplexing for switching between millimeter-wave picocells." international conference on optical and photonic engineering (icOPEN2015). International Society for Optics and Photonics, 2015.

[16] Amphawan, Angela, Sushank Chaudhary, and Brij B Gupta. "Secure MDM-OFDM-Ro-FSO System Using HG Modes." International Journal of Sensors Wireless Communications and Control 5.1 (2015): 13-18.

[17] Amphawan, Angela, et al. "5Gbps HG 0, 1 and HG 0, 3 optical mode division multiplexing for RoFSO." Signal Processing \& Its Applications (CSPA), 2015 IEEE 11th International Colloquium on. IEEE, 2015.

[18] D.Wake, "Radio over Fiber Systems for Mobile Applications

[19] Ali Hussein Radhi, (2013)“ Performance Analysis of Radio over Fiber System with Ook Based Dwdm for Fiber to Home Network", IEEE, Volume 8, Issue 5, PP 26-29

[20] A. J. Cooper, (1990) "Fiber/Radio for the provision of cordless/mobile telephony services in the access," Electronic Letter, vol. 26, pp. 2054-2056,

[21] Sreenesh Shashidharan (2015), "Design and Simulation of Radio Over Fiber System and its Performance Analysis using RZ coding" International Conference on Electrical, Electronics, Signals, Communication and Optimization (EESCO)

[22] Harpreet kaur(2013), "Comparison of NRZ and RZ data modulation formats in SAC-OCDMA system under introduced clock timing jitter of laser diode", International Journal of Advanced Research in Computer and Communication Engineering Vol. 2, Issue 8, Pp $2942-2949$

[23] Arya Mohan(2015), "Full Duplex Transmission in RoF System using WDM and OADM Technology" IJERT Vol. 4 - Issue 01,

[24] Osama A(2013), "High Transmission Capacity Performance of Radio Over Fiber System for Short and
Long Distances “ , International Journal of Science, Engineering and Technology Research (IJSETR) Volume 2, Issue 12 , Pp 2099- 2106

[25] Shuvodip Das(2014), “ Modeling and Performance Analysis of RoF System for Home Area Network with Different Line Coding Schemes Using Optisystem", international journal of multidisciplinary sciences and engineering, vol. 5, no. 6,pp 1-8

[26] Virendra kumar, (2014), "Design and Performance Analysis of Optical Transmission System" ), IOSR Journal of Engineering (IOSRJEN)), Vol. 04, Issue 05 ,PP 22-26,

[27] AbdEl-Naser A. Mohame(2011), “ Transmission Characteristics of Radio over Fiber (ROF) Millimeter Wave Systems in Local Area Optical Communication Networks", Int. J. Advanced Networking and Applications, Volume: 02, Issue: 06, Pp 876-886

[28] Chaudhary, Sushank, Rudrakshi Kapoor, and Abhishek Sharma. "Empirical Evaluation of 4 QAM and 4 PSK in OFDM-based Inter-Satellite Communication System." Journal of Optical Communications.

[29] S. Pachnicke (2012),"Fiber Optical Transmission Systems" Springer.

[30] Mohamed et al. (2012), "High Transmission Performance of Radio Over Fiber Systems over Traditional Optical Fiber Communication Systems Using Different Coding Formats for Long Haul Applications." Nonlinear Optics, Quantum Optics: Concepts in Modern Optics , Vol. 44 Issue 1, p41-63. 23p.

[31] Xiaoqiong qi et al. (2010), "Fiber Dispersion and Nonlinearity Influences on Transmissions of AM and FM Data Modulation Signals in Radio-Over-Fiber System" IEEE journal of quantum electronics Vol. 46, No. 8, Pp. 1170-1177

[32] Sharma, Vishal. "High speed CO-OFDM-FSO transmission system." Optik-International Journal for Light and Electron Optics 125.6 (2014): 1761-1763.

[33] Chaudhary, Sushank, Angela Amphawan, and Kashif Nisar. "Realization of free space optics with OFDM under atmospheric turbulence." Optik-International Journal for Light and Electron Optics 125.18 (2014): 5196-5198

[34] Sharma, Vishal, and Sushank Chaudhary. "Implementation of hybrid OFDM-FSO transmission system." International Journal of Computer Applications $58.8(2012)$

[35] A. Sharma, S. Chaudhary, Neetu, "6 x 20Gbps Long Reach WDM-PI based High Altitude Platform InterSatellite Communication System" International Journal of Computer Applications 122 (22), 41-45

[36] A. Sharma, Neha Chaudhary, S. Chaudhary, "6× 20 Gbps Hybrid WDM-PI Inter-satellite System under the Influence of Transmitting Pointing Errors" Journal of Optical Communications, 2016.

[37] A. Sharma "Analysis and Mitigation of Receiver Pointing Error Angle on Inter-Satellite Communication" International Journal of Innovative Technology and Research 3 (6), 2540-2544 